\title{
Eficácia do herbicida amicarbazone no controle de cordas-de-viola na cultura da cana-de-açúcar (Saccharum spp.) ${ }^{1}$
}

\section{Efficacy of amicarbazone herbicide in controlling morningglories in sugar cane (Saccharum spp.) crop}

\author{
Fernando Tadeu de Carvalho ${ }^{2}$, Juliana R. Gobi Queiroz ${ }^{3}$, Roberto E. Bragion de Toledo ${ }^{4}$
}

Resumo - O objetivo do trabalho foi avaliar a seletividade e a eficácia do herbicida amicarbazone em pré-emergência, no controle de espécies de cordas-de-viola na cultura da canade-açúcar. O experimento foi desenvolvido no período de novembro/2005 a novembro/2006, na Fazenda Santa Terezinha, Pereira Barreto-SP, cultivada pela Usina Pioneiros Bioenergia. O solo do local é do tipo LVE textura média. O experimento foi desenvolvido em área de cana-soca $\left(1^{\circ}\right.$ corte), com a variedade RB 86-5486 e espaçamento de 1,4 m entrelinhas. As espécies de cordasde-viola selecionadas para o experimento: Ipomoea grandifolia, Ipomoea hederifolia, Ipomoea nil, Ipomoea quamoclit e Merremia cissoides foram semeadas em linhas paralelas às linhas da cultura, após a operação de cultivo da cana-de-açúcar. O delineamento experimental foi o de blocos ao acaso, com cinco tratamentos e quatro repetições, com parcelas de $20 \mathrm{~m}^{2}$ (5 x $\left.4 \mathrm{~m}\right)$. Os

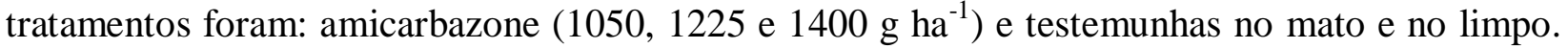
As aplicações foram realizadas em pré-emergência das plantas daninhas, aos 25 dias após a colheita da cana-de-açúcar, utilizando-se um pulverizador pressurizado a $\mathrm{CO}_{2}\left(45 \mathrm{lb} \mathrm{pol}^{-2}\right)$, com barra equipada com quatro pontas da marca Teejet XR110.03, espaçados de 0,5 m e volume de calda de $200 \mathrm{~L} \mathrm{ha}^{-1}$. Concluiu-se que o herbicida amicarbazone (1050, 1225 e $\left.1400 \mathrm{~g} \mathrm{ha}^{-1}\right)$ foi seletivo às plantas de cana-de-açúcar e altamente eficiente no controle das cordas-de-viola: $I$. grandifolia, I. hederifolia, I. nil, I. quamoclit e M. cissoides.

Palavras-Chave: Saccharum spp., Ipomoea, controle químico, pré-emergência.

\begin{abstract}
The objective of the work was to evaluate the selectivity and efficiency of amicarbazone herbicide in pre-emergency, in controlling Ipomoeas species in sugarcane crop. The experiment was developed between November, 2005 to November, 2006, in Santa Terezinha Farm, Pereira Barreto County, São Paulo State, cultivated by Pioneiros Bioenergia Company. The soil of the area is classified as LVE sandy texture. The experiment was developed in area of sugarcane crop of second year (first cut), with RB 86-5486 genotype and spacing of $1.4 \mathrm{~m}$ between lines. Ipomoeas species selected for the experiment: Ipomoea grandifolia, Ipomoea hederifolia, Ipomoea nil, Ipomoea quamoclit and Merremia cissoides, were sowed in parallel lines to the crop lines, after sugarcane cultivation operation. The experimental design was randomized complete blocks, with five treatments and four replications, with plots of $20 \mathrm{~m}^{2}(5 \mathrm{~m}$ x 4m). Treatments were constituted by amicarbazone (1050, 1225 and $1400 \mathrm{~g} \mathrm{ha}^{-1}$ ) and checks, with and without weeds. Applications were accomplished in weeds pre-emergency, at 25 days
\end{abstract}

\footnotetext{
${ }^{1}$ Recebido para publicação em 26/08/2011 e aceito em 14/11/2011.

${ }^{2}$ Professor Dr., DBZ-FEIS-UNESP, Ilha Solteira, SP, Brasil. e-mail: ftadeu@ bio.feis.unesp.br

${ }^{3}$ Pós-graduanda de Agronomia, FEIS-UNESP, Ilha Solteira, SP.

${ }^{4}$ Eng. Agr., Dr., Arysta Lifescience do Brasil Indústria Química e Agropecuária Ltda.
} 
after sugarcane harvest, by using a $\mathrm{CO}_{2}$ pressurized sprayer (45 $\mathrm{lb} \mathrm{pol}^{-2}$ ), with bar equipped with four bar branding tips Teejet XR110.03, spaced of $0.5 \mathrm{~m}$ and spray volume of $200 \mathrm{~L} \mathrm{ha}^{-1}$. It was concluded that amicarbazone herbicide (1050, 1225 and $1400 \mathrm{~g} \mathrm{ha}^{-1}$ ) was selective to sugarcane plants and highly efficient in controlling I. grandifolia, I. hederifolia, I. nil, I. quamoclit and M. cissoides.

Key-words: Saccharum spp., Ipomoea, chemical control, pre-emergency

\section{Introdução}

O Brasil é o maior produtor de cana-deaçúcar do mundo. Segundo dados do IBGE (2011) a área de cultivo de cana-de-açúcar do Brasil na safra 2010/11 foi de 9 milhões de hectares sendo a maior concentração no Estado de São Paulo com 5 milhões de hectares.

O grande potencial edafoclimático do Brasil é uma das condições favoráveis à produção agrícola e em especial à cana-deaçúcar. Entretanto, existe uma série de fatores que podem prejudicar a sua produção. No que diz respeito às plantas daninhas, são observados prejuízos na produtividade da cultura, devido à concorrência por fatores essenciais como água e nutrientes.

As plantas de cana-de-açúcar possuem uma particularidade que lhes permite desenvolver-se bem em diferentes situações de manejo: cana-planta; cana-soca sem palha; cana-soca com palha; cana de $3^{-}, 4^{\stackrel{0}{ }}$ cortes, etc. Entretanto, esta grande variação nos fatores ecológicos proporciona nichos adequados para um grande número de espécies daninhas, o que torna a cana diferente da maioria das outras plantas cultivadas. Desta forma, os herbicidas precisam apresentar um amplo espectro de controle para se adequar às exigências da cultura.

O herbicida amicarbazone é um inibidor de fotossíntese indicado para o controle pré e pós-emergente de plantas daninhas, em canade-açúcar e em milho (Rodrigues \& Almeida, 2005). Entre as espécies suscetíveis ao herbicida indicadas no registro (Arysta
LifeScience, 2007) está a Ipomoea grandifolia, entretanto, na prática tem-se observado também o controle de outras Ipomoeas. Campos et al. (2009) observaram o controle de Ipomoea quamoclit, Ipomoea triloba $\mathrm{e}$ Merremia cissoides utilizando a dose de $980 \mathrm{~g}$ $\mathrm{ha}^{-1}$ de amicarbazone.

As cordas-de-viola (Ipomoea sp.) apresentam problemas de interferência através da competição e dificultando as operações de manejo da cana-de-açúcar (Azania et al., 2002) mas os prejuízos mais evidentes estão relacionados à dificuldade na operação de colheita (Maciel et al., 2007) e, o problema se intensificou nos últimos anos à medida que houve o incremento da colheita mecanizada em cana-de-açúcar (Velini \& Negrisoli, 2000).

O objetivo do trabalho foi avaliar a seletividade e a eficácia do herbicida amicarbazone em pré-emergência no controle de espécies de cordas-de-viola em cana-soca de primeiro corte.

\section{Material e métodos}

O experimento foi desenvolvido no período de novembro/2005 a novembro/2006, na Fazenda Santa Terezinha cultivada pela Usina Pioneiros Bioenergia de Sud Mennucci, localizada no município de Pereira Barreto-SP, nas coordenadas S 20³5'20,7' e WO 51 08'05,5', e 400 metros de altitude. O solo do local é do tipo LATOSSOLO VERMELHO, de textura média, constituído por $30 \%$ de argila, $64 \%$ de areia e $6 \%$ de silte. 
O experimento foi desenvolvido em área de cana-soca (primeiro corte), variedade RB 86-5486 com espaçamento de 1,4 m entrelinhas, colhida 25 dias antes da aplicação dos tratamentos. Os tratos culturais realizados na área experimental, no que diz respeito às adubações e ao controle de pragas, foram os normais exigidos pela cultura e realizados na área de cultivo.

O delineamento experimental adotado foi $\mathrm{o}$ de blocos ao acaso, com cinco tratamentos e quatro repetições. Os tratamentos constaram de duas testemunhas (no mato e no limpo) e três dosagens do herbicida amicarbazone (1050; 1225 e $1400 \mathrm{~g} \mathrm{ha}^{-1}$ ). Cada parcela constou de quatro linhas da cultura com $5 \mathrm{~m}$ de comprimento e $4 \mathrm{~m}$ de largura, totalizando $20 \mathrm{~m}^{2}$. As espécies de cordas-deviola utilizadas no experimento foram: Ipomoea grandifolia, Ipomoea hederifolia, Ipomoea nil, Ipomoea quamoclit e Merremia cissoides, semeadas em linhas paralelas às linhas da cultura (Figura 1), após a operação de cultivo da cana-de-açúcar.

As características do herbicida utilizado no experimento são as seguintes. Nome comercial: Dinamic $^{\circledR}$. Ingrediente ativo: amicarbazone. Grupo químico: Triazolinona. Concentração do ingrediente ativo: $700 \mathrm{~g} \mathrm{~kg}^{-1}$. Formulação: grânulos dispersíveis em água. Toxicidade: classe toxicológica: II. Fabricante: Arysta Lifescience do Brasil Indústria Química e Agropecuária Ltda.

As aplicações do herbicida foram realizadas com um pulverizador costal com pressão constante $\left(\mathrm{CO}_{2}\right)$ de $45 \mathrm{lb} \mathrm{pol}^{2}$ e provido de tanque com capacidade de dois litros (garrafas descartáveis), e com barra equipada com quatro pontas do tipo leque, Teejet XR110.03, espaçadas de 0,5 metro. $O$ volume de calda aplicado foi de $200 \mathrm{~L} \mathrm{ha}^{-1}$. As aplicações foram realizadas em pré-emergência das plantas daninhas (Figura 2) aos 25 dias após a colheita da cana-de-açúcar, no dia 10/11/2006, das 6:00 hs. às 7:00 hs. Na ocasião, o solo encontrava-se com umidade, com rajadas de ventos inferior $4 \mathrm{~km} \mathrm{~h}^{-1}$, e temperatura e umidade relativa do ar observadas no final das aplicações de $23^{\circ} \mathrm{C}$ e $70 \%$, respectivamente.

Espécie 5: Merremia cissoides

LINHA DE CANA-DE-AÇÚCAR

Espécie 4: Ipomoea grandifolia

Espécie 3: Ipomoea nil

LINHA DE CANA-DE-AÇÚCAR

Espécie 2: Ipomoea grandifolia

Espécie 1: Ipomoea quamoclit

LINHA DE CANA-DE-AÇÚCAR

Figura 1. Distribuição da semeadura das plantas daninhas nas entrelinhas da cultura, dentro das parcelas. Pereira Barreto-SP (2005/06). 

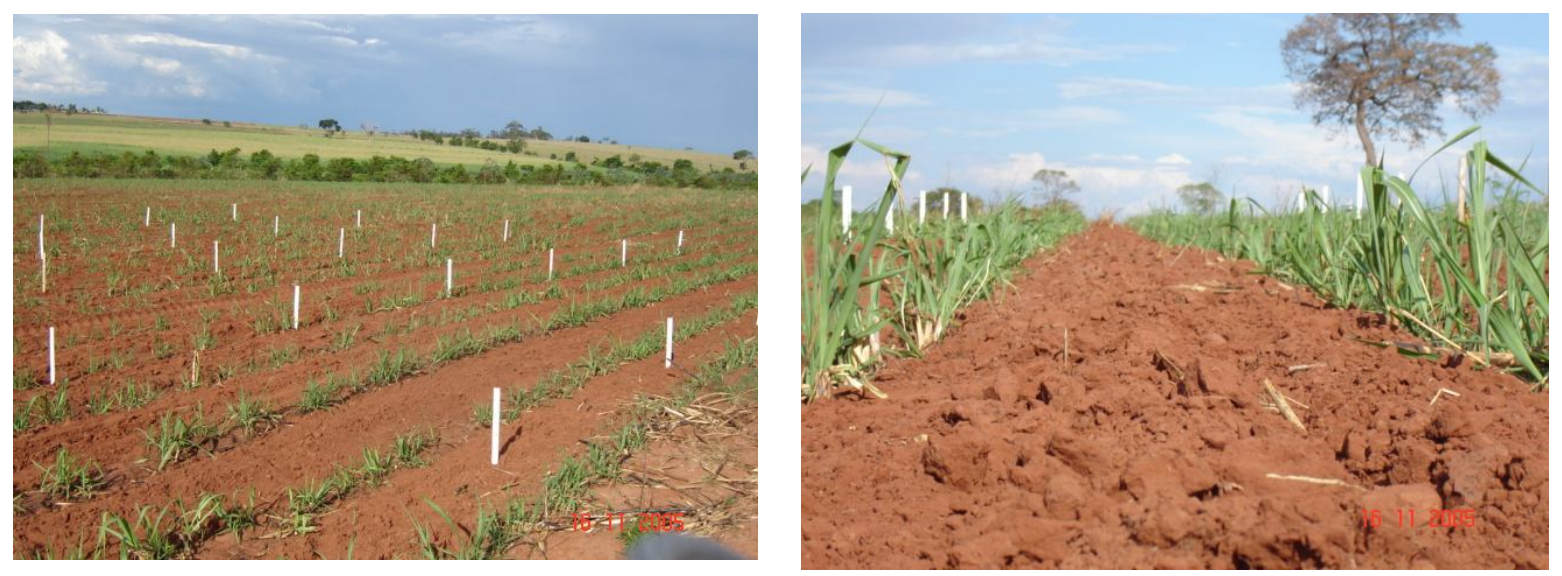

Figura 2. Estádio de desenvolvimento da cultura por ocasião da aplicação dos tratamentos. Pereira Barreto-SP (2005/06).

As características do herbicida utilizado no experimento são as seguintes. Nome comercial: Dinamic ${ }^{\circledR}$. Ingrediente ativo: amicarbazone. Grupo químico: Triazolinona. Concentração do ingrediente ativo: $700 \mathrm{~g} \mathrm{~kg}^{-1}$. Formulação: grânulos dispersíveis em água. Toxicidade: classe toxicológica: II. Fabricante: Arysta Lifescience do Brasil Indústria Química e Agropecuária Ltda.

As aplicações do herbicida foram realizadas com um pulverizador costal com pressão constante $\left(\mathrm{CO}_{2}\right)$ de $45 \mathrm{lb} \mathrm{pol}^{2}$ e provido de tanque com capacidade de dois litros (garrafas descartáveis), e com barra equipada com quatro pontas do tipo leque, Teejet XR110.03, espaçadas de 0,5 metro. O volume de calda aplicado foi de $200 \mathrm{~L} \mathrm{ha}^{-1}$. As aplicações foram realizadas em pré-emergência das plantas daninhas (Figura 2) aos 25 dias após a colheita da cana-de-açúcar, no dia 10/11/2006, das 6:00 hs. às 7:00 hs. Na ocasião, o solo encontrava-se com umidade, com rajadas de ventos inferior a $4 \mathrm{~km} \mathrm{~h}^{-1}$, e temperatura e umidade relativa do ar observadas no final das aplicações de $23^{\circ} \mathrm{C}$ e $70 \%$, respectivamente.
A eficiência dos herbicidas no controle das plantas daninhas foi avaliada aos 15, 30, 45, 60 e 75 dias após a aplicação, utilizando-se uma escala visual, onde $0 \%=$ nenhum controle e $100 \%=$ controle total das plantas daninhas, conforme metodologia citada por SBCPD (1995). Considerou-se como eficiente o controle igual ou superior a $80 \%$ aos 75 DAA, época em que foi realizada a ultima avaliação. A seletividade dos tratamentos às plantas da cultura foi avaliada visualmente, considerandose a biomassa e a coloração das plantas tratadas comparadas com as plantas da testemunha e atribuindo-se notas de $0 \%$ a $100 \%$, onde $0 \%=$ nenhum sintoma de fitotoxicidade e $100 \%=$ morte das plantas.

Os resultados obtidos foram submetidos à análise de variância pelo teste $\mathrm{F}$, e as suas médias comparadas pelo teste de Tukey, em nível de significância de 5\%.

\section{Resultados e Discussão}

As infestações médias das plantas daninhas na área experimental, nas testemunhas sem capinas, aos 30 dias após a aplicação (DAA) dos tratamentos foram as 
seguintes: 92,8 plantas/m de Ipomoea grandifolia; 58,5 plantas/m de Ipomoea hederifolia; 40,5 plantas/m de Ipomoea nil; 38,3 plantas/m de Ipomoea quamoclit e 38,5 plantas/m de Merremia cissoides. Os dados de porcentagem de controle das plantas daninhas na avaliação realizada aos 75 DAA estão contidos na Tabela 1.

Tabela 1. Controle de Ipomoeas por amicarbazone em cana-de-açúcar. Pereira Bareto, SP (2005/06).

\begin{tabular}{lcccccc}
\hline \multirow{2}{*}{ TRATAMENTOS } & \multirow{2}{*}{$\begin{array}{c}\text { Dosagem } \\
\left(\mathrm{g} \mathrm{ha}^{-1}\right)\end{array}$} & $\begin{array}{c}\text { Ipomoea } \\
\text { grandifolia }\end{array}$ & $\begin{array}{c}\text { Ipomoea } \\
\text { hederifolia }\end{array}$ & $\begin{array}{c}\text { Ipomoea } \\
\text { nil }\end{array}$ & $\begin{array}{c}\text { Ipomoea } \\
\text { quamoclit }\end{array}$ & $\begin{array}{c}\text { Merremia } \\
\text { cissoides }\end{array}$ \\
\hline 1- testemunha no mato & -- & 0,0 & 0,0 & 0,0 & 0,0 & 0,0 \\
2- testemunha no limpo & -- & 100,0 & 100,0 & 100,0 & 100,0 & 100,0 \\
3- amicarbazone & 1050 & 99,8 & 98,5 & 100,0 & 99,3 & 100,0 \\
4- amicarbazone & 1225 & 100,0 & 99,5 & 100,0 & 100,0 & 100,0 \\
5- amicarbazone & 1400 & 100,0 & 100,0 & 100,0 & 100,0 & 100,0 \\
\hline
\end{tabular}

Obs.: DAA= Dias Após a Aplicação

Observou-se pelos dados de controle das plantas daninhas que os tratamentos foram eficazes no controle das cinco espécies de corda-de-viola. Na primeira avaliação, aos 15 DAA, observou-se a germinação das cordasde-viola em todos os tratamentos e o início do processo de fitointoxicação destas plantas daninhas. Na segunda avaliação (30 DAA) o controle já era praticamente total em todos os tratamentos. Esse tipo de sintoma é o esperado para os herbicidas deste grupo químico (inibidores do FS II), segundo Vidal (1997).

O herbicida amicarbazone, nas dosagens de 1050, 1225 e $1400 \mathrm{~g} \mathrm{ha}^{-1}$ foi altamente eficiente no controle das cordas-deviola, proporcionando níveis médios de controle acima de 98,5\%, aos 75 DAA, para as todas as espécies de Ipomoeas. Os dados observados estão de acordo com as recomendações de Lorenzi et al. (2006).
Campos et al. (2009), também observaram o controle de I. quamoclit, I. triloba e $M$. cissoides utilizando a dose de $980 \mathrm{~g} \mathrm{ha}^{-1} \mathrm{de}$ amicarbazone.

Os dados médios de fitotoxicidade do herbicida e de produtividade da cultura estão apresentados na Tabela 2. Observou-se que os tratamentos provocaram sintomas muito leves de fitotoxicidade inicial (15 DAA) à cultura. Aos 30 DAA os sintomas foram menores e, aos 45 DAA, não foi observado nenhum sintoma às plantas de cana-de-açúcar. Os baixos índices de fitotoxicidade demonstram a alta seletividade do herbicida às plantas de cana-de-açúcar. Os dados de produtividade da cultura confirmam a seletividade do herbicida: observa-se que todos os tratamentos foram significativamente superiores à testemunha no mato. 
Tabela 2. Dados médios de fitointoxicação causada pelos herbicidas e de produtividade da cultura da cana-de-açúcar. Pereira Barreto-SP (2005/06).

\begin{tabular}{lccccc}
\hline \multirow{2}{*}{ Tratamentos } & Dosagem & \multicolumn{3}{c}{ Fitointoxicação (\%) } & Produtividade \\
\cline { 3 - 5 } & $\left(\mathrm{g} \mathrm{ha}^{-1}\right)$ & $15 \mathrm{DAA}$ & $30 \mathrm{DAA}$ & $45 \mathrm{DAA}$ & $\left(\mathrm{t} \mathrm{ha}^{-1}\right)$ \\
\hline 1- testemunha no mato & -- & $0,0 \mathrm{c}$ & $0,0 \mathrm{c}$ & 0,0 & $105,18 \mathrm{~b}$ \\
2- testemunha no limpo & -- & $0,0 \mathrm{c}$ & $0,0 \mathrm{c}$ & 0,0 & $118,00 \mathrm{a}$ \\
3- amicarbazone & 1050 & $2,8 \mathrm{~b}$ & $1,5 \mathrm{~b}$ & 0,0 & $117,13 \mathrm{ab}$ \\
4- amicarbazone & 1225 & $3,3 \mathrm{ab}$ & $2,8 \mathrm{a}$ & 0,0 & $118,10 \mathrm{a}$ \\
5- amicarbazone & 1400 & $4,8 \mathrm{a}$ & $3,0 \mathrm{a}$ & 0,0 & $118,15 \mathrm{a}$ \\
\hline Média & 2,15 & 1,45 & -- & 115,31 \\
\hline teste f (para tratamentos) & $34,57^{*} *$ & $27,67 * *$ & -- & $4,24 *$ \\
\hline Coeficiente de Variação (\%) & 33,16 & 37,77 & -- & 4,78 \\
\hline DMS (5\%) & 1,61 & 1,24 & -- & 12,44 \\
\hline
\end{tabular}

Obs.: DAA= Dias Após a Aplicação.

- Médias seguidas por mesma letra, na coluna, não diferem entre si pelo teste de Tukey a 5\% de probabilidade.

* - significativo a $5 \% ; * *$ - significativo a $1 \% ;{ }^{\text {ns }}$ - Não significativo

\section{Conclusão}

Considerando as condições em que o trabalho foi desenvolvido, concluiu-se que o herbicida amicarbazone, nas doses de 1050, $1225 \mathrm{e} 1400 \mathrm{~g} \mathrm{ha}^{-1}$, foi seletivo às plantas de cana-de-açúcar (cana-soca, primeiro corte, variedade $R B$ 86-5486) e foi altamente eficiente no controle das cordas-de-viola: $I$. grandifolia, I. hederifolia, I. nil, I. quamoclit e M. cissoides.

\section{Referências}

ARYSTA LIFESCIENCE. Produtos. Disponível em: <http://www.hokko.com.br/ globalsite/>. Acesso em: 08/12/2007.

AZANIA, A.A.P.M. et al. Interferência da palha de cana-de-açúcar (Saccharum spp.) na emergência de espécies daninhas da Família Convolvulaceae. Planta Daninha, v.20, n.2, p.207-212, 2002.

CAMPOS, L.H.F. et al. Suscetibilidade de Ipomoea quamoclit, I. triloba e Merremia cissoides aos herbicidas sulfentrazone e amicarbazone. Planta Daninha, v.27, n.4, p.831-840. 2009.

INSTITUTO BRASILEIRO DE GEOGRAFIA E ESTATÍSTICA - IBGE. Levantamento Sistemático da Produção Agrícola - Canade-açúcar - Safra 2011. Disponível em: <http://www.ibge.gov.br/home/estatistica/indic adores/agropecuaria.> Acesso em: 15/03/2011.

LORENZI, H. et al. Manual de Identificação e controle de plantas daninhas: plantio direto e convencional, $6^{-}$ed., Nova Odessa: Plantarum, 2006. 339 p.

MACIEL, C.D.G. et al. Cana - Corda-de-viola. Caderno Técnico da Revista Cultivar. Pelotas, n.95, 2007. 7 p.

RODRIGUES, B.N.; ALMEIDA, F.S. Guia de herbicidas. $5^{\text {a }}$ ed., Londrina: Edição dos Autores, 2005. 592 p.

SBCPD. Procedimentos para instalação, avaliação e análise de experimentos com herbicidas. Londrina: SBCPD, 1995, 42 p.

VELINI, E.D.; NEGRISOLI, E. Controle de plantas daninhas em cana crua. In: 
CONGRESSO BRASILEIRO DA CIÊNCIA DAS PLANTAS DANINHAS, 22., 2000, Foz do Iguaçu. Anais... Foz do Iguaçu: Sociedade Brasileira da Ciência das Plantas Daninhas, 2000, p.148-164.

VIDAL, R.A. Herbicidas: Mecanismos de ação e resistência de plantas. Porto Alegre: Ed. do Autor, 1997. 165 p. 